\title{
Quarterly Index
}

\section{WOMEN AND THE INTERNET}

Women make up $46 \%$ of Internet users in Canada, but they are much more likely than men to use the Internet for health purposes. Among female and male Internet users, $45 \%$ of the women said they used the Internet for information pertaining to health, health organizations, health products, natural health products
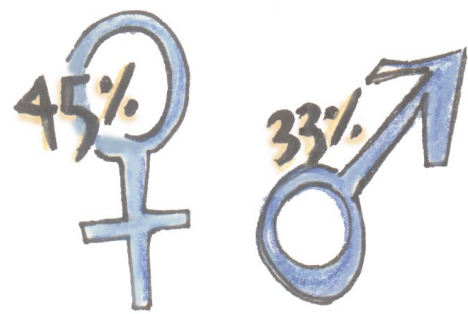
and similar activities, according to the latest survey of The Berger Population Health Model. By contrast, only $33 \%$ of the male Internet users said they used it for healthrelated purposes.

\section{THE INTERNET AND LOCAL INFORMATION}

The Monitor survey, conducted in May 2000, found that despite the talk of global access to health information and resources on the Internet, $84 \%$ of Internet users said it was very or somewhat important that the health sites they visit contain information regarding Canadian resources and professionals.

\section{health @ canada.}

\section{PRIVACY ON THE INTERNET}

A harbinger of difficulties associated with maintaining accurate records, for marketing and consumer response programs, is the admission by $39 \%$ of Internet users that they do not register with health web sites. Of the remaining Internet users, almost half $(48 \%)$ say they always, often or sometimes, provide incomplete or inaccurate personal information in order to protect their privacy.

\section{PRESCRIBING PATTERNS ACROSS CANADA}

The Monitor found that some two-thirds of Canadians report they have received a prescription for medication in the previous year. However, in Quebec only 58\% say they have received a prescription.

Canadians receiving a prescription for medication in the past year..

National

$65 \%$

Atlantic

$67 \%$

Quebec

$58 \%$

Ontario

$68 \%$

Manitoba and Saskatchewan 69\%

Alberta

$64 \%$

British Columbia

$65 \%$

Among those receiving prescriptions, there are also significant regional variations among those currently taking two or more scripts:

Taking 2 or more scripts...

National

$41 \%$

Atlantic

$47 \%$

Quebec

$39 \%$

Ontario

$42 \%$

Manitoba and Saskatchewan 47\%

Alberta

$37 \%$

British Columbia

$29 \%$

It is not clear why people are much less likely to be taking two or more prescription medications in British Columbia than in the Atlantic provinces or in Manitoba and Saskatchewan. The proportion of seniors in those provinces is similar. One of the reasons may be differences in provincial drug programs; and another may be differences in informal patterns of prescribing and clinical care.

\section{$\bigoplus_{\text {wu. }}$ pharmacy.ca}

Data supplied by The Berger Monitor Highlight Report, and based on results from the May 2000 survey administered by Environics Research Group among 2,526 Canadians 15 years of age and older.

Topics in The Berger Monitor, which continues The Canada Health Monitor surveys of health issues in Canada, are prepared in consultation with The Hay Health Care Consulting Group. For more information contact: Earl Berger, Managing Director by telephone at 416 815-6405 or email at Earl_Berger@haygroup.com 